\title{
Weibull-Based Design Methodology for Rotating Structures in Aircraft Engines
}

\author{
Erwin V. Zaretsky and Robert C. Hendricks \\ National Aeronautics and Space Administration, Glenn Research Center, Cleveland, Ohio, USA \\ Sherry Soditus \\ United Airlines Maintenance, San Francisco, California, USA
}

The NASA Energy-Efficient Engine ( $E^{3}$-Engine) is used as the basis of a Weibull-based life and reliability analysis. Each component's life, and thus the engine's life, is defined by high-cycle fatigue or low-cycle fatigue. Knowing the cumulative life distribution of each of the components making up the engine as represented by a Weibull slope is a prerequisite to predicting the life and reliability of the entire engine. As the engine's Weibull slope increases, the predicted life decreases. The predicted engine lives $L_{5}(95 \%$ probability of survival) of approximately 17,000 and $32,000 \mathrm{hr}$ do correlate with current engine-maintenance practices without and with refurbishment, respectively. The individual high-pressure turbine (HPT) blade lives necessary to obtain a blade system life $L_{0.1}(99.9 \%$ probability of survival) of $9000 \mathrm{hr}$ for Weibull slopes of 3,6 , and 9 are 47,$391 ; 20,652$; and $15,658 \mathrm{hr}$, respectively. For a design life of the HPT disks having probable points of failure equal to or greater than $36,000 \mathrm{hr}$ at a probability of survival of $99.9 \%$, the predicted disk system life $L_{0.1}$ can vary from 9408 to $24,911 \mathrm{hr}$.

Keywords Design, Engine, Failure, Life, Turbine, Weibull

The classic approach to aircraft engine component design has been deterministic. The deterministic method assumes that full and certain knowledge exists for the service conditions and the material strength. Specific equations with specific material and fluid characteristics then define an engine component's operating conditions. They are coupled with experience-based safety factors to predict the component's performance, life, and

Received 26 July 2002; accepted 26 July 2002.

Address correspondence to Erwin V. Zaretsky, NASA Glenn Research Center, 21000 Brookpark Road, Cleveland, OH 44135, USA. E-mail: erwin.v.zaretsky@grc.nasa.gov

reliability. Variability in heat treatment, loading, and operating profile, among other variables, is not necessarily factored into these equations. This omission can result in large variances in the component's performance, life, and reliability from those predicted. Being able to design for manufacturing and operational variation and to accept a defined risk can be a valuable design tool.

Palmgren (1924) suggested a probabilistic approach to predicting the lives of machine components and, more specifically, of rolling-element bearings. On the basis of his test results, he suggested that an acceptable life be defined as that time at which $10 \%$ of a population of bearings will have failed or $90 \%$ will have survived. He also noted that there was an apparent effect of size on life. That is, larger bearings with the same equivalent load as smaller bearings had shorter lives than the smaller bearings (Zaretsky, 1998).

Weibull (1939a, 1939b) published two papers that describe a statistical approach to determining the strength of solids. Weibull postulated that the dispersion in material, or fracture strength, of a homogeneous group of test specimens can be expressed according to the following relationship:

$$
\ln \ln \frac{1}{S}=e \ln \left[\frac{X}{X_{\beta}}\right]
$$

where $X=\sigma$ and $X_{\beta}=\sigma_{\beta}$ (Weibull, 1951). The derivation of the Weibull distribution function can be found in Melis, Zaretsky, and August (1999).

Equation (1) relates the probability of survival $S$ and the fracture (or rupture) strength $\sigma$. When $\ln \ln (1 / S)$ is used as the ordinate and $\ln \sigma$ or $\ln N$ as the abscissa, fracture and fatigue data are assumed to plot as a straight line shown in Figure 1. The slope (tangent) of this line is referred to as the "Weibull slope" or "Weibull modulus," usually designated by the letter $e$. The Weibull slope is indicative of the dispersion of the data and its density (statistical) distribution. Weibull slopes of 1,2, and 3.57 are indicative of exponential, Raleigh, and normal (gaussian) 


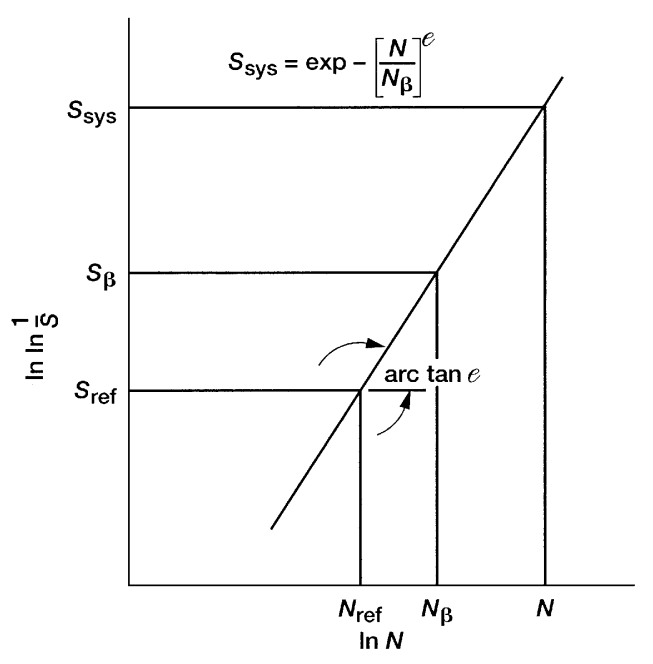

FIGURE 1

Sketch of Weibull plot where the Weibull slope, or the tangent of the line, is $e . S_{\beta}$ is the probability of survival of $36.8 \%$, at which $N=N_{\beta}$ or $N / N_{\beta}=1$. (From Melis, Zaretsky, and August, 1999.)

distributions, respectively (Weibull, 1962). The plot itself is referred to as a "Weibull plot."

Weibull (1939a, 1939b) further related the probability of survival $S$, the material strength $\sigma$, and the stressed volume $V$ according to the following relation:

$$
\ln \frac{1}{S}=\int_{V} f(X) \mathrm{d} V
$$

where for a given probability of survival $S=S_{o}$,

$$
\ln \frac{1}{S_{o}}=C_{o}=V_{o} f(X)
$$

Letting

$$
f(X)=\sigma^{e}
$$

it follows that $\sigma$ is inversely related to $V_{o}$ where the exponent is the inverse of the Weibull slope,

$$
\sigma=\left[\frac{C_{o}}{V_{o}}\right]^{1 / e}
$$

or in general for any $S, V$,

$$
\sigma \sim\left[\frac{1}{V}\right]^{1 / e}
$$

In 1947, Lundberg and Palmgren applied Weibull analysis to the prediction of rolling-element-bearing fatigue life. The
Lundberg-Palmgren theory expressed $f(X)$ in Equation (2) as

$$
f(X)=\frac{\tau^{c} N^{e}}{Z^{h}}
$$

where $\tau$ is the critical shear stress, $N$ is the number of stress cycles to failure, and $Z$ is the depth to the maximum critical shear stress in a concentrated (hertzian) contact.

For a given probability of survival $S$,

$$
N \sim\left[\frac{1}{\tau}\right]^{c / e}\left[\frac{1}{V}\right]^{1 / e}\left[\frac{1}{Z}\right]^{-h / e}
$$

In Lundberg and Palmgren (1947) the parameter $c / e$ is the stress-life exponent. This implies that the inverse relation of life with stress is a function of the life scatter or data dispersion. A search of the literature for a wide variety of materials suggests that the stress-life exponent is independent of Weibull slope $e$. Also, from observation, and contrary to the Lundberg-Palmgren assumption, fatigue life appears to be independent of the depth to the maximum critical shear stress in a body. Hence, Zaretsky (1994) has modified the Lundberg-Palmgren theory, where

$$
f(X)=\tau^{c e} N^{e}
$$

For a given probability of survival $S$,

$$
N \sim\left[\frac{1}{\tau}\right]^{c}\left[\frac{1}{V}\right]^{1 / e}
$$

Zaretsky (1987), as well as Ioannides and Harris (1985), proposed a generalized Weibull-based methodology for structural life prediction that uses a discrete-stressed-volume approach. Zaretsky, Smith, and August (1989) applied this methodology to qualitatively predict the life of a rotating generic disk with circumferentially placed holes as a function of the various Weibull parameters. August and Zaretsky (1993) extended the methodology of Zaretsky to allow for calculating the local probability of failure within any component's stressed volume as well as within the entire component based on finite-element stress analysis. Holland, Zaretsky, and Melis (1998) applied this method to predicting the fracture strength and life of a metal-matrix composite ring using coupon data to determine the Weibull parameters. Zaretsky, Poplawski, and Peters (1996) and Poplawski, Zaretsky, and Peters (2001a, 2001b) applied the Zaretsky method to predict the lives of ball and roller bearings. Melis and Ogonek (1995) implemented this life-prediction methodology through a computer code called Probable Cause.

Melis, Zaretsky, and August (1999), using the method of Zaretsky and the computer code Probable Cause, analyzed the lives of two different groups of aircraft gas turbine engine compressor disks for which there existed limited fatigue data (Mahorter et al., 1985). These disks were manufactured from a titanium (Ti-6Al-4V) alloy. A reasonable correlation was obtained between the disk lives predicted by using the computer 
code Probable Cause and those predicted by using a modified crack-growth-life-prediction method. For both methods, at a failure probability of $0.1 \%$ ( $99.9 \%$ probability of survival), the life of the first group of disks was slightly overpredicted, and the life of the second group of disks was significantly underpredicted. The failure probability analysis for both disk groups predicted with reasonable engineering certainty the failure locations at the bolt holes of each disk. These locations correlated with those observed experimentally.

Using the Weibull analysis and the Lundberg-Palmgren theory, Lewicki and colleagues (1986) determined the fatigue life of an Allison T56/501-D22A gearbox based on a typical operating profile. Excellent correlation was obtained between the predicted lives and actual field data. To the best of our knowledge, a Weibull-type reliability (failure probability) analysis similar to that of Lewicki and colleagues (1986) has not been performed on an aircraft gas turbine engine as an entire system.

The NASA Lewis Research Center (now the Glenn Research Center) developed an experimental aircraft engine incorporating technologies new at the time. The engine and the program were known as the Energy-Efficient Engine, or $\mathrm{E}^{3}$-Engine (Figure 2; Davis and Stearns, 1985). Most of these technologies have been incorporated in both currently flying commercial and military engines. Using the $\mathrm{E}^{3}$-Engine as a basis for analysis, it is the objective of the work reported herein to (1) demonstrate and apply a Weibull probability analysis to its rotating components based upon a low- or high-cycle fatigue criteria for removal and (2) determine engine life and reliability based upon the cumulative life distributions of individual engine rotating components.

\section{WEIBULL PROBABILITY ANALYSIS}

A typical scenario that can be adopted to design an aircraft engine for life and reliability is to assume a typical flight (profile) cycle and specify a life in flight hours and a reliability for the engine. Usually an engine is removed for cause, degraded performance, or because it has reached its specified design life. Any engine event that will require removal of the engine from the aircraft or removal of the aircraft from scheduled service can be designated a failure. The engine can be removed or repaired for cause or for an expired time before an anticipated failure can occur. A component in the engine can be failed when it is no longer fit for its intended purpose even though it is still functional. A component is removed before it can cause secondary damage to the engine.

When specifying a design life, an acceptable reliability also needs to be specified; that is, how many incidents of engine removal for cause is the end-user airline willing to experience before the engine's design life is reached? As an example, if there were a fleet of 1000 engines and the end user were willing to accept that 50 engines would be removed for cause before the design life was reached, the engine could be considered to operate at a $5 \%$ removal (failure) rate or at a $95 \%$ probability of survival. This number does not anticipate "infant mortality" or "human factors" in the analysis. Although, based on experience or a previously existing data base, these causes may be factored into a final analysis. However, for the purpose of this article and the resulting analysis, infant mortality and human factors are not considered.

Figure 3 shows, generically, a typical flight profile for the NASA $E^{3}$-Engine (Davis and Stearns, 1985). There are 15 power settings for this engine during the flight cycle. Using the required engine-design life of this typical flight cycle at a $95 \%$ probability of survival, the engine life can be determined at each power setting using the linear damage (Palmgren-Langer-Miner) rule (Langer, 1937; Miner, 1945; Palmgren, 1924) where

$$
\frac{1}{\mathbf{L}_{\mathrm{sys}}}=\frac{X_{1}}{\mathbf{L}_{1}}+\frac{X_{2}}{\mathbf{L}_{2}}+\cdots \frac{X_{n}}{\mathbf{L}_{n}}
$$

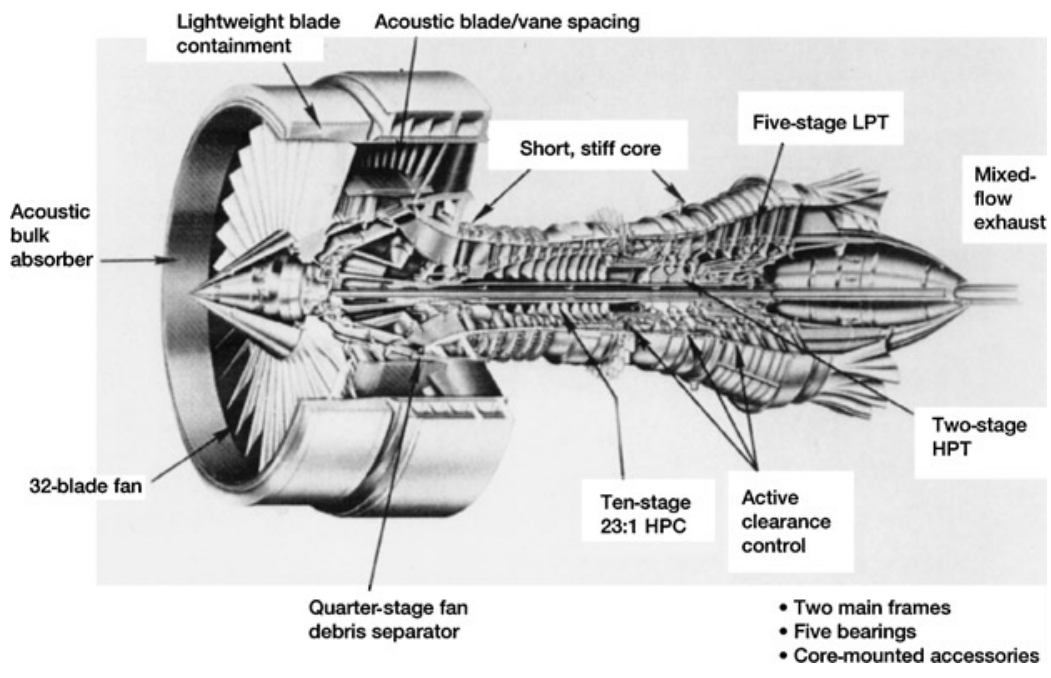

FIGURE 2

Cutaway of $\mathrm{E}^{3}$-engine flight propulsion system (FPS) illustrating its features. (From Davis and Stearns, 1985.) 


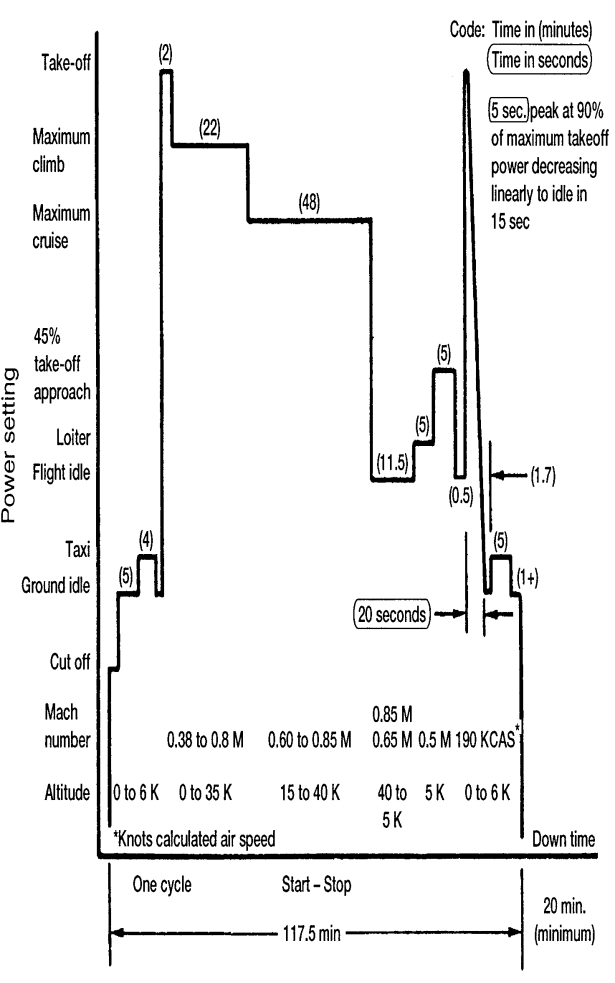

FIGURE 3

$\mathrm{E}^{3}$-engine typical flight cycle. (From Davis and Stearns, 1985.)

and assuming that the engine life is directly proportional to the engine thrust load $T$ (power setting) to a power $p$ where

$$
L \sim \frac{1}{T^{p}}
$$

The cumulative life of each of the engine components illustrated in the Weibull plots of Figure 4 can be combined to determine the calculated engine-system life $L_{\text {sys }}$ using the LundbergPalmgren formula (Lundberg and Palmgren, 1947):

$$
\frac{1}{L_{\mathrm{sys}}^{e}}=\frac{1}{L_{1}^{e_{1}}}+\frac{1}{L_{2}^{e_{2}}}+\cdots+\frac{1}{L_{n}^{e_{n}}} .
$$

Equation (11) is derived from Weibull Equation (1) and is found in Melis, Zaretsky, and August (1999).

The value of the Weibull slope or modules $e$ can be different for each component system and between elements within a component system. Where the cumulative distribution function of engine removal for cause, as represented by a Weibull slope, is not known, it is not unreasonable to use the value of the Weibull slope of the cumulative distribution of the shortest lived component system within the engine to represent that of the engine.

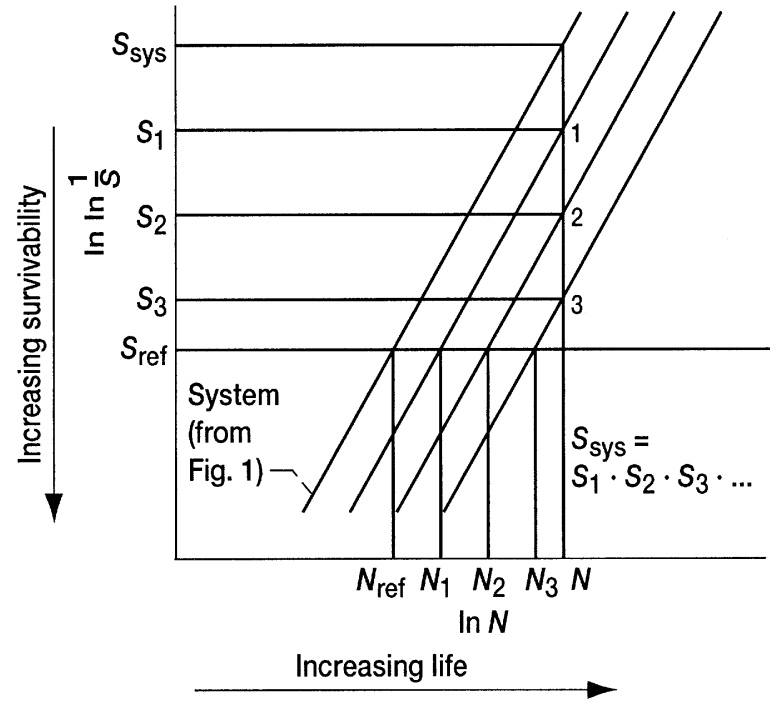

FIGURE 4

Sketch of multiple Weibull plots in which each numbered plot represents the cumulative distribution of each component in a system, and the system's Weibull plot represents the combined distribution of plots 1, 2, 3, etc. All plots are assumed to have the same Weibull slope $e$. (From Melis, Zaretsky, and August, 1999.)

\section{ENERGY-EFFICIENT ENGINE}

The NASA $E^{3}$-Engine (see Fig. 2) was used as the basis of the Weibull-based life and reliability analysis reported in this article. The engine, which was successfully fabricated and tested, was a "clean-sheet" derivative of the GE CF6-50C engine. A summary of the NASA $E^{3}$-Engine was described by Davis and Stearns (1985). A review of the gas-path fluid dynamics was described by Hall and colleagues (1998). Details of the rolling-element-bearing support system were described by Broman (1982) and those of the high-pressure turbine (HPT) were described by Halila, Lenahan, and Thomas (1982).

A typical flight cycle for the $\mathrm{E}^{3}$-Engine flight propulsion system (FPS) is shown in Figure 3. Table 1 summarizes the engine-thrust load and time at each power setting, as shown in Figure 3. The $\mathrm{E}^{3}$-FPS engine cycle pressure ratio at maximum climb is 38.4 with a bypass ratio of 6.7. The fan-pressure ratio at maximum climb is 1.7 with a turbine inlet temperature of $1343^{\circ} \mathrm{C}\left(2450^{\circ} \mathrm{F}\right)$ static, warm-day takeoff. The installed enginespecific fuel consumption at maximum cruise is $0.0575 \mathrm{~kg} /$ $\mathrm{N}-\mathrm{hr}(0.564 \mathrm{lb}$-fuel/lb-thrust-hr) with a thrust range of 162.4 to $173.5 \mathrm{kN}\left(36,500\right.$ to $\left.39,000 \mathrm{lb}_{\mathrm{f}}\right)$. The rotating components of interest are as follows:

1. Fan

2. Quarter-stage fan booster

3. High-pressure compressor (HPC)

4. High-pressure turbine

5. Low-pressure turbine (LPT)

6. Rolling-element bearings 
TABLE 1

$\mathrm{E}^{3}$-Engine Thrust Fraction with Typical Flight Conditions as Shown in Figure 3

\begin{tabular}{lcccc}
\hline $\begin{array}{l}\text { Flight propulsion } \\
\text { system based on } \\
\begin{array}{c}\mathrm{E}^{3} \text {-engine } \\
\text { condition }\end{array}\end{array}$ & $\begin{array}{c}\text { Thrust } \\
\text { (fraction) }\end{array}$ & $\begin{array}{c}\text { Engine } \\
\text { speed } \\
\text { (fraction) }\end{array}$ & $\begin{array}{c}\text { Maximum } \\
\text { cruise } \\
\text { thrust } \\
\text { (fraction) }\end{array}$ & $\begin{array}{c}\text { Time at } \\
\text { power }^{a} \\
\text { (min) }\end{array}$ \\
\hline Takeoff & 1.00 & 1.00 & 1.18 & $2^{b}$ \\
Maximum climb & .85 & .95 & 1.00 & 22 \\
Maximum cruise & .65 & .9 & .76 & 48 \\
Approach & .45 & .825 & .53 & 5 \\
Loiter $^{c}$ & .33 & .78 & .39 & 5 \\
Flight idle & .25 & .76 & .29 & $12^{d}$ \\
Taxi & .13 & .72 & .15 & 9 \\
Ground idle & .07 & .7 & .08 & 8.7 \\
Cutoff & .05 & & .04 & $1.5+$ \\
\hline
\end{tabular}

${ }^{a}$ Total flight time, $117.5 \mathrm{~min}$.

${ }^{b}$ Includes thrust reverse 20 -sec transient $5 \mathrm{sec}$ up to $15 \mathrm{sec}$ down.

${ }^{c}$ Usually 0.3 thrust fraction.

${ }^{d}$ Flight idle varies from 11.5 to $16.5 \mathrm{sec}$.

Each of the component systems cited above is summarized in Table 2. For example, the number of elements in the fan represents the number of blades. The hours are representative of the service life of that element (or elements) of the component. Davis and Stearns (1985) and Halila, Lenahan, and Thomas (1982) define an engine cycle as one flight hour.

The fan has shrouded blades and a quarter-stage booster under an untrapped island, and outlet guide vanes are an integral part of the fan frame. The low-aspect-ratio fan blade is to meet bird-ingestion requirements and the quarter-stage fan booster configuration is to mitigate foreign-object damage (FOD) to the core and compressor.

The compressor achieves a 23:1 compression ratio in 10 stages, with the inlet guide vane (IGV) and the first four stators being variable. Active clearance control is used to enhance cruise performance and reduce deterioration. The unboosted configuration in combination with the two-stage turbine provides better specific fuel consumption ( $\mathrm{sfc}$ ).

The combustor is a double annular arrangement that provides low emissions and shorter engine length. Because combustor removal usually occurs for reasons other than fatigue, the combustor life is not included in this investigation.

The two-stage, high-pressure turbine has a high wheel speed (e.g., 12,627 rpm, nominal $518 \mathrm{~m} / \mathrm{sec}(1700 \mathrm{ft} / \mathrm{sec})$ tip speed) and extended-life requirements demand a clean design with $56 \%$ of the HPT power extracted by the first stage. The blades/vanes are moderately loaded. Compressor discharge air cools the first stage, and seventh-stage air cools the second stage. The case clearance is actively controlled from the fan duct air.

The five-stage, low-pressure turbine is also moderately loaded. It is a low-throughflow design close coupled with the
TABLE 2

$E^{3}$-Engine Components and New (2000) Engine Technology or Experience-Based Life Assessment

\begin{tabular}{c}
$\begin{array}{c}\text { New engines before } \\
\text { parts are removed } \\
\text { or repaired }\end{array}$ \\
\hline
\end{tabular}

\begin{tabular}{|c|c|c|c|}
\hline $\begin{array}{l}\text { Major rotating } \\
\text { components }\end{array}$ & $\begin{array}{l}\text { Number of } \\
\text { elements }\end{array}$ & $\begin{array}{l}\text { Allowable } \\
\text { (cycles) }\end{array}$ & $\begin{array}{c}\text { Typical } \\
\text { (hr) }\end{array}$ \\
\hline \multicolumn{4}{|l|}{ Fan } \\
\hline Hub & 1 & 20,000 & \\
\hline Blades/stators & $32 / 34$ & & 25,000 \\
\hline \multicolumn{4}{|l|}{ Compressor-Low } \\
\hline \multicolumn{4}{|c|}{ 1/4-Stage-low-drum (3507 rpm) } \\
\hline Disk & 1 & 20,000 & 25,000 \\
\hline Stators/blades & $60 / 56$ & & 25,000 \\
\hline Inlet guide vanes & 64 & & 25,000 \\
\hline \multicolumn{4}{|c|}{ Compressor-HPC-drum-11,600 rpm } \\
\hline Forward shaft stub & 1 & 20,000 & \\
\hline Inlet guide vanes & 32 & & 25,000 \\
\hline Disks & 11 & 20,000 & \\
\hline Stage 1 stators/blades & $50 / 28$ & & 25,000 \\
\hline Stage 2 stators/blades & $68 / 38$ & & 25,000 \\
\hline Stage 3 stators/blades & $82 / 50$ & & 25,000 \\
\hline Stage 4 stators/blades & $92 / 60$ & & 25,000 \\
\hline Stage 5 stators/blades & $110 / 70$ & & 25,000 \\
\hline Stage 6 stators/blades & $120 / 80$ & & 25,000 \\
\hline Stage 7 stators/blades & $112 / 82$ & & 25,000 \\
\hline Stage 8 stators/blades & $104 / 84$ & & 25,000 \\
\hline Stage 9 stators/blades & $118 / 88$ & & 25,000 \\
\hline Stage 10 stators/blades & $140 / 96$ & & 25,000 \\
\hline Seal-bolt flange-disk & 1 & 20,000 & \\
\hline
\end{tabular}

Combustor transition drum

20,000

Turbine-HPT-drum

Disks

$\begin{array}{ccc}2 & 20,000 & \\ 46 / 76 & & 25,000 \\ 1 & 20,000 & \\ 48 / 70 & & 25,000 \\ 1 & 20,000 & \end{array}$

Nozzles/blades

T1-T2 Inner seal bolt flange disk

Stage 2 stators/blades

T2 Seal bolt disk bearing flange

Turbine-LPT-drum

Disks

Stage 3 stators/blades

Stage 4 stators/blades

Stage 5 stators/blades

Stage 6 stators/blades

Stage 7 stators/blades

Bearing system

No. 1 angular contact ball: engine support 
TABLE 2

$E^{3}$-Engine Components and New (2000) Engine Technology or Experience-Based Life Assessment (Continued)

\begin{tabular}{lccc}
\hline & & $\begin{array}{c}\text { New engines before } \\
\text { parts are removed } \\
\text { or repaired }\end{array}$ \\
\cline { 3 - 4 } $\begin{array}{c}\text { Major rotating } \\
\text { components }\end{array}$ & $\begin{array}{c}\text { Number of } \\
\text { elements }\end{array}$ & $\begin{array}{c}\text { Allowable } \\
\text { (cycles) }\end{array}$ & $\begin{array}{c}\text { Typical } \\
\text { (hr) }\end{array}$ \\
\hline $\begin{array}{l}\text { No. } 2 \text { angular contact } \\
\text { ball: core thrust }\end{array}$ & 1 & \\
$\begin{array}{l}\text { No. } 3 \text { cylindrical roller: } \\
\text { HP-spool }\end{array}$ & 1 & \\
$\begin{array}{c}\text { No. } 4 \text { cylindrical roller: } \\
\text { HP-spool }\end{array}$ & 1 & \\
$\begin{array}{l}\text { No. } 5 \text { cylindrical roller: } \\
\text { engine support }\end{array}$ & 1 & \\
\hline
\end{tabular}

high-pressure turbine. The case is full-round rather than split and has a high aspect ratio, tip-shrouded blades, and disks connected to form a drum supported by a single cylindrical roller bearing. The LPT cooling air is fifth-stage compressor air. Active clearance control (ACC) also uses fan-bleed air.

The engine is supported on a forward ball bearing at the fan and an aft roller bearing within the LPT. The loads are carried out through the fan and turbine struts to the pylon mountings on the wing. The high-spool forward support is carried by a roller bearing near the HPC inlet guide vane and an aft roller bearing near the LPT inlet. The thrust bearing in the vicinity of the HPC inlet guide vane is a split-inner-ring, angular-contact ball bearing.

\section{ENGINE-MAINTENENCE PRACTICE}

\section{Service Life}

The service life of an aircraft gas turbine engine is based upon deterministic calculations of low-cycle fatigue (LCF) and previous field experience with like and similar engines. It is probable that no two engine companies determine the life of their engines in the same way or apply the same experience and safety factors to their designs. This can be readily illustrated by the reported life estimates of the NASA E ${ }^{3}$-Engine. Davis and Stearns (1985) determined the life of an engine based upon its similarity to their maintenance experience with a commercial engine having similarly designed components. These life estimates are shown in Table 3.

The life in hours shown assumes that before the times shown, there will be no failures. Hence, where the service life is listed as $9000 \mathrm{hr}$, the engine is removed from the aircraft and inspected. Routine maintenance is performed. The component designated under the column "Service life" is either repaired and/or replaced.
TABLE 3

$E^{3}$-Engine Flight Propulsion-System Life Based on 1985 Technology and Experience

\begin{tabular}{lrc}
\hline & $\begin{array}{c}\text { Service life } \\
(\mathrm{hr})\end{array}$ & $\begin{array}{c}\text { Total life with } \\
\text { repair }(\mathrm{hr})\end{array}$ \\
\hline Combustor & 9000 & 18,000 \\
HPT rotating structure & 18,000 & 36,000 \\
HPT blading & 9000 & 18,000 \\
Remainder of engine & & 36,000 \\
\hline
\end{tabular}

From Davis and Stearns, 1985.

In the column "Total life with repair," the part is removed from service and/or the usable life of the engine has been reached. This scenario assumes that all engines will operate and fail in a like and similar manner at a designated time and that removal is required before that time is reached. Table 3 does not anticipate any cause for engine removal prior to those times listed except from engine performance degradation.

\section{Causes of Engine Removal \\ Engine Performance Degradation}

There are numerous factors to consider before an engine is repaired or refurbished. The primary reason for engine removal is performance deterioration. This condition can be tracked with relative ease and the engine removal can be planned and scheduled. Performance deterioration can be a decline in engine efficiency in either the compressors or the turbines, loss of engine stability or surge margin, or exhaust-gas temperature (EGT) limits that can cause "overtemping" of the turbines. Deteriorating engine efficiency and rising EGT, in most cases, are a steady progression and can be monitored through engine-conditionmonitoring (ECM) programs. Deterioration or loss in engine stability cannot be tracked by means of ECM. The engine has to be periodically tested to check for sufficient surge margin (not all engine types will experience this condition).

Engine performance degradation is measured in terms of the EGT margin. During the engine development, a single probe or multiple probes are placed downstream of the HTP to protect it (and nozzles) from excessive turbine inlet temperatures (T41). A baseline correlation is established between the temperature measurement downstream of the HPT and the T41. An EGT margin of $17^{\circ} \mathrm{C}\left(30^{\circ} \mathrm{F}\right)$ might be correlated with an $83^{\circ} \mathrm{C}$ $\left(150^{\circ} \mathrm{F}\right)$ change in $\mathrm{T} 41$. So the T41 redline may be at $1538^{\circ} \mathrm{C}$ $\left(2800^{\circ} \mathrm{F}\right)$, and an EGT margin of $17^{\circ} \mathrm{C}\left(30^{\circ} \mathrm{F}\right)$ would indicate operation at a $\mathrm{T} 41$ of $1455^{\circ} \mathrm{C}\left(2650^{\circ} \mathrm{F}\right)$. This temperature may affect engine operations so that clearances begin to erode, blades roughen, coatings degrade, bearings wear, or fuel nozzles clog or coke, as engine efficiency deteriorates. To maintain the same thrust level required by the flight profile, more fuel loading is required (emissions increase as well) and the engine speed is increased. Increased fuel loading then increases T41, for example, 
to $1482^{\circ} \mathrm{C}\left(2700^{\circ} \mathrm{F}\right)$. The EGT margin takes into consideration all the combinations of adverse conditions that the engine may encounter. As an engine approaches a 0-EGT margin, it is removed for refurbishment as a precaution against operating under adverse conditions.

When the engine is pulled for refurbishment, all components are inspected, and damaged components are replaced or repaired. The engine is reassembled and a new performance EGT margin is determined on the engine test stand. There are three important things to note:

1. No two engines perform alike, whether they are new, refurbished, or repaired.

2. EGT margins characterize each engine and, like a fingerprint, are not the same but can be averaged over the fleet.

3. EGT margins of today's new engines are, on average, higher than those for refurbished or repaired engines: 12,000 to $20,000 \mathrm{hr}$ on a new engine versus 5000 to $15,000 \mathrm{hr}$ on a refurbished or repaired engine. Some engines can be repaired on the wing.

\section{Foreign-Object Damage}

FOD can cause an engine to be removed from service, depending upon the extent of the damage. However, if the damage is light, the engine can be left on the wing and the damage repaired. One of the most common causes of FOD is ingestion of birds. All engines are required by the certification process to be able to ingest a predetermined number of birds without incurring engine shutdown. However, even with the design requirements, an engine may ingest a flock of birds or, on a rare occasion, ingest a larger-than-designed-for bird, and damage to the engine blades may result. Other causes of FOD are accreted ice and runway debris that the engine picks up and ingests during takeoff or landing.

\section{Hardware Deterioration}

Even when an engine is operating properly, it can experience some form of hardware deterioration that requires engine removal. One good example is the deterioration of the HPT blades. An engine is borescoped periodically to determine its health. It is not uncommon to find that the HPT blades deteriorate in service because of the extreme operating conditions they encounter. Depending upon the condition of the deterioration, an engine may be allowed to remain in service on a decreased-cycle inspection interval until it is determined that the deterioration is beyond limits and the engine must be removed.

\section{Oil Consumption}

A high oil consumption (HOC) condition will cause an engine to be removed from service. The causes of an HOC condition are numerous and include broken oil lines, oil leakage around the mainline bearing carbon seals, and coking in bearing compartments because of an air leak. Significant loss of oil during flight will cause an engine to be shut down and subsequently removed from service.

\section{Other Causes}

An engine in service may be performing perfectly but may be removed because one or more of its rotating parts has run up against a hard time or cycle limit. On rare occasions, an engine may be included in what is considered a quality escape, wherein it has been determined that there is a problem with a batch of parts used in assembling a group of engines.

Another cause of engine removal is the failure of a component or rotating part that causes an in-flight shutdown (IFSD) event or an uncontained failure. Finally, due to a known safety-related problem, an engine may be removed because of a federally mandated airworthiness directive (AD) note.

\section{ENGINE REPAIR AND REFURBISHMENT}

Operation of the airline industry is very expensive and the profit margin is extremely small. In general, new technology, first-run engines will get upwards of $20,000 \mathrm{hr}$ of operation before refurbishment. Operating times for second-run engines before refurbishment are shorter than those of first-run engines. Each and every engine that is brought in for repair or refurbishment is given special consideration so that the work scope of the engine is correct.

The following is a general guide for module refurbishment of engines removed for performance deterioration:

Fan Fan refurbishment each time; a big driver in performance and relatively inexpensive to do

LPC Minor refurbishment at first engine shop visit and major refurbishment every other visit; generally, severe conditions not seen by LPC

HPC Refurbished at a major shop visit; tip clearances restored, restored efficiency

HPT Refurbished at a major shop visit; most deterioration seen by the components

LPT Refurbished every other major shop visit; not a big driver in performance deterioration

Bearings Bearings refurbished or restored at each major shop visit; rolling-element fatigue (spalling) possibly experienced by number 1 angular-contact ball bearing (generally, bearings run well and trouble free and rarely are the cause of engine removal)

When an engine is removed from service and shipped to the refurbishment shop, the engine and its individual module performance are evaluated and the root cause of removal determined. If an engine is removed for performance or hardware deterioration or a major part failure, the engine will be, in most cases, completely broken down into modules. Then each module will be refurbished. Generally, the high-spool section of the engine (the HPC, combustor, T1-nozzles, and HPT) will be refurbished at every major engine-shop visit. The low-spool section of the 
engine (fan, LPC, and LPT) will be individually evaluated as to the need or level of refurbishment required. Because the lowspool section does not experience conditions as severe as those of the high spool, the level of refurbishment can be lower and the time between refurbishment can be extended.

It is always good practice to refurbish the fan blades during the engine-shop visit. With the large-bypass fan engines, restoring the efficiency of the fan is relatively easy and results in a big return on investment in service.

If an engine has been removed for cause, such as an IFSD event, HOC, quality escape, maintenance errors, or the like, the cause of the engine's removal will be evaluated, together with the age of the engine and each module age and the current performance of the engine and each module. An engine that is performing well may be repaired and returned to service for another couple of years, or the refurbishment of the engine may be more extensive.

The major nonrotating structure of an engine can be used indefinitely as long as the components are replaced and repaired, and the new performance EGT margin is positive. Hence, the serial number life can be considered indefinite.

\section{RESULTS AND DISCUSSION}

The NASA $E^{3}$-Engine (see Figure 2) was used as the basis of the Weibull-based life and reliability analysis reported in this article. The engine, which was successfully fabricated and tested, was a clean-sheet derivative of the GE CF6-50C engine. Each of the component systems of interest for this investigation and analysis is summarized in Table 3, which represents 1985 engine technology and experience in comparison with Table 2, which summarizes typical hours of service in engine technology of 2000 before parts are inspected or repaired on comparable components.

\section{Failure Criteria}

In practice, the various engine companies have different methods of determining component and system lives and reliabilities. That is, it would not be unreasonable to expect that the life and reliability of the same component might have distinctly different values were they to be calculated or determined by each of the independent companies. These numbers are based on stress analysis, laboratory test data, field experience, life factors, and engineering judgment. They are for the most part deterministic and do not assume or anticipate incipient failure or cause for removal prior to the designated time.

Many design engineers use a probabilistic approach wherein a normal or log-normal distribution is assumed about a calculated or experimental mean value of life and a $99.9 \%$ probability of survival is calculated. As previously discussed, this would imply that 1 in 1000 of the same components would be removed for cause prior to reaching the calculated or projected time.

Davis and Stearns (1985) and Halila, Lenahan, and Thomas (1982) discussed the mechanical analytical methods and proce- dures for turbine engine and HPT design. The designs for the engine components are based on life predictions by using material test curves that relate life in cycles or time (hr) as a function of stress. Six criteria for failure were presented:
1. Stress rupture
2. Creep
3. Yield
4. Low-cycle fatigue (LCF)
5. High-cycle fatigue (HCF)
6. Fracture mechanics

A discussion of each criterion above is beyond the scope of this article. However, it can reasonably be concluded that items 1 and 2 are defined by steady-state stress and time at load and temperature. Items 3 and 6 are defined by stress and temperature and are generally considered to be independent of time. Where limits are placed on stress, temperature, and time for a component's design, the criteria that will define the component's life and thus the engine's life will be either HCF or LCF. At high temperatures, it is difficult to determine a fatigue limit or a stress below which no failure will occur for most aerospace materials. Failures are statistically distributive; that is, the ratio of time between the first component failure and the last in a population can be 1 or 2 orders of magnitude. All materials and components will not have the same cumulative failure distribution curve (Weibull slope).

A major omission made by many in determining the life and reliability of the various components is consideration of each component's size (stressed volume) and the number of components of a given type and design in the operating system. This omission was recognized by Weibull (1939a, 1939b) and is incorporated as a stressed-volume effect in Equations (2) through (8). For example, for a given stress distribution, a turbine disk having less material volume or a smaller number of bolt holes will have a longer LCF life at a given probability of survival than a larger disk of the same design (Zaretsky, Smith, and August, 1989). In many designs, the life of a single component is incorrectly based on the life of the stressed-volume that has the highest single-stressed value, independent of other stressed points in the body. This can result in overpredicting the component's life (Melis, Zaretsky, and August, 1999). It is also not possible to accurately relate individual coupon fatigue and fracture strength data to component life and reliability without considering the effect of stressed volume or the number of elements in the system (Zaretsky, 1987).

\section{Effect of Weibull Slope on Life Estimation}

In Equation (1), the Weibull slope is designated by the symbol $e$ and is indicative of the dispersion of engine or component failure or replacement data for an entire engine or a single component when plotted on Weibull coordinates. As previously discussed, Weibull slopes $e$ of 1,2, and 3.57 are representative of exponential, Raleigh, and normal (gaussian) distributions. The life distribution of a component and thus the Weibull slope is a function of the material from which it is made, the manufacturing 
process, including tolerances, and the operating variables that deviate from defined steady-state conditions. Because of the lack of a definitive statistical database, the statistical distributions and thus the Weibull slope of most, if not all, engine components is assumed or estimated. The effect of this estimation on life and reliability prediction prior to this study has not been evaluated.

\section{Engine Life}

When predicting engine life and reliability, knowing the Weibull slope of each of the components that make up the engine is a prerequisite to predicting the life and reliability of the entire engine. It is also important for logistic planning to determine the rate at which components and engines will need replacement or repair. As previously discussed, Davis and Stearns (1985) and Halila, Lenahan, and Thomas (1982) determined the life of an engine based upon its similarity to their maintenance experience with a commercial engine having similarly designed components. These life estimates are shown in Table 3. We assumed that the life estimates in Table 3 represent the $99.9 \%$ probability of survival for each of the component systems. Using Equation (11), we calculated the life of the entire engine at a 95 and a $99.9 \%$ probability of survival for the assumed combinations of Weibull slopes shown in Table 4 for the HPT blade, the HPT rotating structure, and the remainder of the engine as follows:

$$
\frac{1}{L_{\text {sys }}^{e_{\text {sys }}}}=\frac{1}{L_{\mathrm{HPT} \text { blade }}^{e_{1}}}+\frac{1}{L_{\mathrm{HPT} \text { ROT.ST. }}^{e_{2}}}+\frac{1}{L_{\mathrm{RE}}^{e_{3}}}
$$

Since we assumed that the general cause for removal of the combustor is erosion wear and not fatigue, we did not include it in our life calculations. The Weibull slope for the entire engine system was assumed to be the same as that for the turbine blades. According to Davis and Stearns (1985) and Halila, Lenahan, and Thomas (1982), the HPT blades are the shortest lived components in this engine.

The results of our analysis are shown in Table 4 . The $L_{0.1}$ and $L_{5}$ lives are the times on or before which 0.1 and $5 \%$ of the engines will be removed from service for cause, respectively. That is, out of 1000 engines, one engine will be removed at the $L_{0.1}$ life and 50 engines will be removed at the $L_{5}$ life. The least variation and longest predicted lives occur with an assumed engine Weibull slope of 3 . This is nearly a normal distribution. As an engine's Weibull slope increases, the predicted life decreases, and there is greater variation and sensitivity to variation in each individual component's Weibull slope. Although we do not know with reasonable engineering certainty that these assumed distributions (Weibull slopes) actually represent those found in an engine, they show that errors and vast differences in predicted life and engine replacement can occur. The predicted $L_{5}$ lives of $\sim 17,000$ and $32,000 \mathrm{hr}$, which are dependent on the Weibull slopes assumed, do correlate with current engine maintenance practices without and with refurbishment, respectively. That is, it can be reasonably anticipated that at one of these time inter-

\section{TABLE 4}

Effect of Cumulative Distribution of Individual Component Lives on Predicted Engine Life and Reliability Based Upon Component $L_{0.1}$ Lives Shown in Table 3

\begin{tabular}{|c|c|c|c|c|}
\hline \multicolumn{3}{|c|}{ Weibull slope, $e$} & \multirow{2}{*}{\multicolumn{2}{|c|}{ Predicted engine life (hr) }} \\
\hline \multirow{2}{*}{$\begin{array}{l}\text { Turbine } \\
\text { blades }\end{array}$} & \multirow{2}{*}{$\begin{array}{c}\text { Turbine } \\
\text { disks }\end{array}$} & \multirow{2}{*}{$\begin{array}{c}\text { All other } \\
\text { components }\end{array}$} & & \\
\hline & & & $L_{0.1}$ & $L_{5}$ \\
\hline \multicolumn{5}{|c|}{ Engine Weibull slope, $e=3$} \\
\hline \multirow[t]{10}{*}{3} & 3 & 3 & 8606 & 32,009 \\
\hline & & 6 & 8645 & 32,154 \\
\hline & & 9 & 8645 & 32,158 \\
\hline & 6 & 3 & 8945 & 33,270 \\
\hline & & 6 & 8991 & 33,471 \\
\hline & & 9 & 8992 & 33,445 \\
\hline & 9 & 3 & 8945 & 33,270 \\
\hline & & 6 & 8992 & 33,445 \\
\hline & & 9 & 8992 & 33,445 \\
\hline & & ine Weibull sl & pe, $e=$ & \\
\hline \multirow[t]{10}{*}{6} & 3 & 3 & 131 & 252 \\
\hline & & 6 & 134 & 258 \\
\hline & & 9 & 134 & 258 \\
\hline & 6 & 3 & 189 & 364 \\
\hline & & 6 & 8943 & 17,237 \\
\hline & & 9 & 8944 & 17,239 \\
\hline & 9 & 3 & 189 & 364 \\
\hline & & 6 & 8967 & 17,283 \\
\hline & & 9 & 8967 & 17,283 \\
\hline & & ine Weibull sl & pe, $e=$ & \\
\hline \multirow[t]{9}{*}{9} & 3 & 3 & 26 & 40 \\
\hline & & 6 & 26 & 40 \\
\hline & & 9 & 26 & 40 \\
\hline & 6 & 3 & 33 & 51 \\
\hline & & 6 & 685 & 1061 \\
\hline & & 9 & 686 & 1062 \\
\hline & 9 & 3 & 30 & 51 \\
\hline & & 6 & 1090 & 1688 \\
\hline & & 9 & 8990 & 13,923 \\
\hline
\end{tabular}

vals, $5 \%$ of the engines in service will have been removed for repair or refurbishment for cause.

\section{Component Lives}

Turbine Disk Life

An error that is frequently made in life prediction, whether for aerospace or nonaerospace application, is the assumption that the life of a combination of the same components in a system will be the same as that of the single shortest lived component in that system. For a single component, the life of that component is incorrectly taken to be the life of the most highly stressed element in the body, or what is referred to as the probable point 


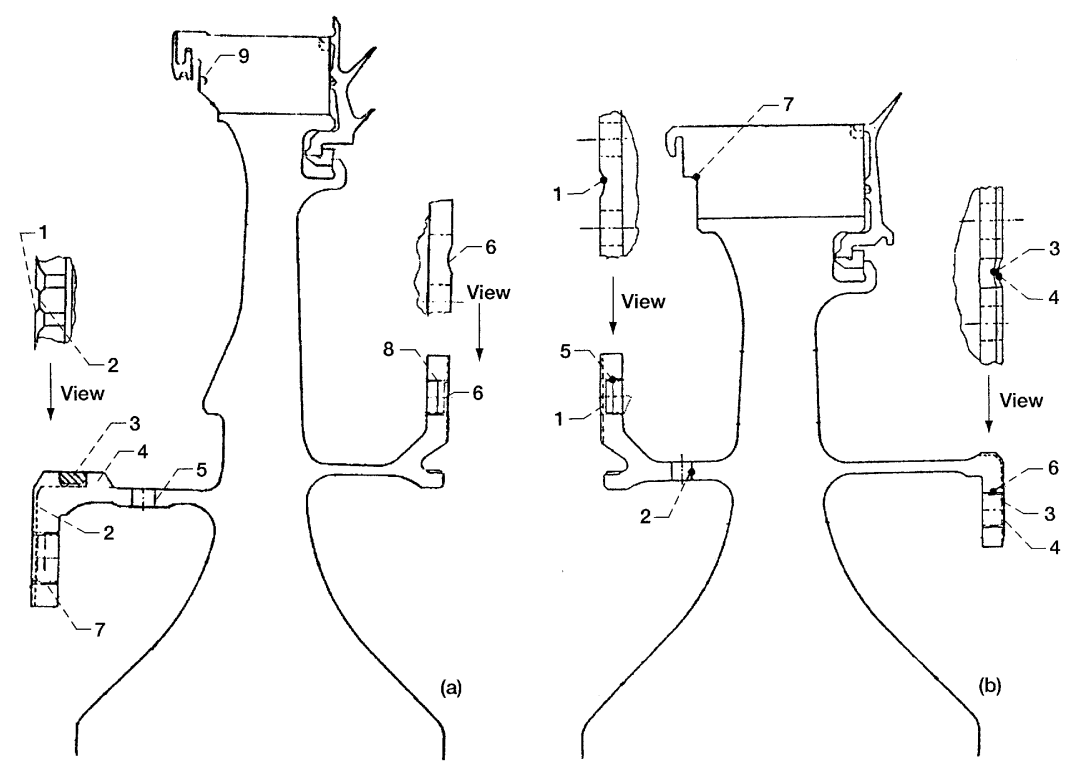

FIGURE 5

Cross-sectional schematic of high-pressure turbine disk stress concentration and LCF life locations. (a) T1 disk; (b) T2 disk. See Table 5 for locations and definitions. (From Halila, Lenahan, and Thomas, 1982.)

of failure (ppf). This error can be illustrated by the $\mathrm{E}^{3}$-Engine high-pressure turbine disk-life calculations for T1 and T2 disk stress concentrations, as shown in Figure 5 (Halila, Lenahan, and Thomas, 1982) and as summarized in Table 5.

Halila, Lenahan, and Thomas (1982) imply that the design life of the disk is equal to or greater than $36,000 \mathrm{hr}$ at a probability of survival of $99.9 \%$ based on the calculated life at the location of the forward-arm air hole for the T1 disk (see Table 5a and Figure 5a). Using the data from Halila, Lenahan, and Thomas (1982), which account only for the ppf, we recalculated the disk lives individually and as a system based upon Equaion (11). For our calculations, we assumed Weibull slopes of 3, 6, and 9 and that the section shown in Figure 5 repeats in 15-degree segments of the disk, accounting for multiple elements. The results are shown in Table 6. From this table, one sees that the predicted $L_{0.1}$ system life can vary from 9408 to $24,911 \mathrm{hr}$, depending on the Weibull slope assumed.

\section{Blade Life}

The HPT blades present a similar problem with regard to determining their lives. Initially, the time to removal of these blades is determined by a creep criterion that is deterministic or, at least, is not assumed to be probabilistic. This criterion is dependent on time exposure at stress and temperature. Material test data are used to predict rupture life based on calculated stress and temperature. Throughout an engine cycle these combinations of stress and temperature vary, so the linear damage (Palmgren-Langer-Miner) rule (Equation (9)) can be applied to determine the retirement times of the blade.

Blade-coating life is another time-limiting criterion for removal and repair. The blades are usually removed when the engine is removed from service for other reasons and, as necessary, the remaining coating is removed by chemical stripping or machining and is replaced. The coating life usually does not dictate blade replacement, only repair.

Besides creep, the limiting time for blade replacement is HCF. As with LCF, HCF is probabilistic. The blades are subject to vibratory stresses combined with mechanical stresses caused by centrifugal loads, gas aerodynamic loads, and thermal loads. Because of the variations in operating conditions, the lineardamage rule can also be applied to the operating profile of the blades to determine their life.

For the $\mathrm{E}^{3}$-Engine, the HPT blades were designed for a system life of $18,000 \mathrm{hr}$, with repairs permissible after the first $9000 \mathrm{hr}$ of engine operation. No reliability was specified by Davis and Stearns (1985) or Halila, Lenahan, and Thomas (1982) for the 9000-hr life. However, we assumed for this discussion and for subsequent calculations that the designated time is at a $99.9 \%$ reliability for the combination of all the blades contained on disks 1 and 2. Disks 1 and 2 hold 76 and 70 blades, respectively, for a total of 146 blades. Again, assuming Weibull slopes of 3, 6, and 9 , we determined the life of an individual blade at a $99.9 \%$ probability of survival using Equation (11):

$$
L_{\text {blade }}=\left(n L_{\text {sys }}^{e}\right)^{(1 / e)}=\left(146 \times 9000^{e}\right)^{(1 / e)}
$$

The individual blade lives necessary to obtain a blade system life of $9000 \mathrm{hr}$ at a $99.9 \%$ probability of survival for Weibull slopes of 3, 6, and 9 were 47,391; 20,652; and 15,658 hr, respectively. Based on these individual blade lives and 1000 engines, or 146,000 blades in service, plus a retirement time for the blades of $18,000 \mathrm{hr}$ constituting the total blade life with repair, it would 
TABLE 5

$\mathrm{E}^{3}$-Engine High-Pressure Turbine Disk Stress Concentration and Low-Cycle Fatigue (LCF) Life Material René 95

\begin{tabular}{|c|c|c|c|c|c|}
\hline Location & $\begin{array}{l}\text { Nominal stress } \\
(\mathrm{MPa}(\mathrm{ksi}))\end{array}$ & $\begin{array}{c}\text { Stress } \\
\text { intensity factor } \\
K_{t} \sigma ; \mathrm{Mpa}(\mathrm{ksi})\end{array}$ & $\begin{array}{l}\text { Critical } \\
\text { time }^{a} \\
(\mathrm{sec})\end{array}$ & $\begin{array}{c}\text { Temperature } \\
\left({ }^{\circ} \mathrm{C}\left({ }^{\circ} \mathrm{F}\right)\right)\end{array}$ & $\begin{array}{c}\mathrm{LCF}^{b} \text { life } \\
\text { (kilocycles) }\end{array}$ \\
\hline \multicolumn{6}{|c|}{ (a) $\mathrm{T} 1$ disk, Figure 5(a) } \\
\hline 1. Forward arm air-passage slot & $448(65)$ & $841(122)$ & 875 & $541(1006)$ & $>100$ \\
\hline 2. Forward arm flange air-passage slot and scallop & $269(39)$ & $731(106)$ & 40 & $427(800)$ & $>100$ \\
\hline 3. Forward arm ring container & $331(48)$ & 945 (137) & 40 & $458(857)$ & $>100$ \\
\hline 4. Forward arm scallop & $393(57)$ & $565(82)$ & 875 & $545(1013)$ & $>100$ \\
\hline 5. Forward arm air hole & $455(66)$ & $1103(160)$ & 875 & 544 (1012) & 36 \\
\hline 6. Aft arm air-passage slot & $400(58)$ & $469(68)$ & 875 & $553(1027)$ & $>100$ \\
\hline 7. Forward arm bolt hole & $421(61)$ & $938(136)$ & 875 & $541(1006)$ & $>100$ \\
\hline 8. Aft arm bolt hole & $434(63)$ & $931(135)$ & 875 & $552(1025)$ & $>100$ \\
\hline 9. Disk post notch & $276(40)$ & $827(120)$ & 40 & $527(980)$ & $>100$ \\
\hline \multicolumn{6}{|c|}{ (b) T2 disk, Figure 5(b) } \\
\hline 1. Forward arm air-passage slot & $407(59)$ & $476(69)$ & 875 & $552(1025)$ & $>100$ \\
\hline 2. Forward arm air hole & $427(62)$ & $1082(157)$ & 875 & $451(1023)$ & 45 \\
\hline 3. Aft arm flange double slot & $441(64)$ & $731(106)$ & 875 & $513(955)$ & $>100$ \\
\hline 4. Aft arm flange air slot & $648(94)$ & $752(109)$ & 875 & $518(965)$ & $>100$ \\
\hline 5. Forward arm flange bolt hole & $427(62)$ & $931(135)$ & 875 & $552(1005)$ & $>100$ \\
\hline 6. Aft arm flange bolt hole & $455(66)$ & $993(144)$ & 875 & $517(963)$ & 60 \\
\hline 7. Disk post notch & $234(64)$ & $703(102)$ & 40 & $338(640)$ & $>100$ \\
\hline
\end{tabular}

${ }^{a}$ Critical time, time from throttle burst at takeoff.

${ }^{b}$ Low-cycle fatigue.

From Halila, Lenahan, and Thomas, 1982.

be expected that 8,64 , or 512 blades would be removed for cause prior to this time for Weibull slopes of 3,6 , or 9, respectively.

\section{Other Components}

A similar analysis can be performed for the fan blades and hub, quarter-stage fan booster disks and blades, high-pressure compressor disks and blades, low-pressure turbine disks and blades, and rolling-element bearings. In fact, this type of analysis has been performed to determine the life of rolling-element bearings individually and as a system for nearly 5 decades (Zaretsky, 1992). Once all the component lives are determined at a given probability of survival (or at a given replacement rate), the

\section{TABLE 6}

Predicted Life of High-Pressure Turbine Disks as Function of Weibull Slope

\begin{tabular}{lccr}
\hline \multirow{2}{*}{$\begin{array}{c}\text { Weibull slope, } \\
e\end{array}$} & \multicolumn{3}{c}{$0.1 \%$ life $L_{0.1}{ }^{a}(\mathrm{hr})$} \\
\cline { 2 - 4 } 3 & Disk 1 Figure 5(a) & Disk 2 Figure 5(b) & System \\
\hline 6 & 11,228 & 12,646 & 9408 \\
9 & 21,136 & 25,634 & 20,195 \\
\hline
\end{tabular}

${ }^{a} 99.9 \%$ probability of survival. removal rate for cause of the entire engine can be predicted with reasonable engineering certainty.

\section{GENERAL COMMENTS}

The use of deterministic methods to predict engine component life and reliability can improperly predict both the actual removal rate of the component in service and the resultant service life of the engine. The use of mean or median lives coupled with an assumed statistical distribution can distort the life-prediction process. Field data can indicate significantly shorter lives than the predicted lives, a situation that can result in economy- and safety-related issues for airlines. Conversely, component lives that are too short can be predicted, and this can result in premature component removal and heavy costs to airlines.

The key to economic viability and flight safety is to predict with reasonable engineering certainty individual component and resultant engine lives and to be able to remove them from service for repair or refurbishment before secondary damage can occur because of a failed part. As has been pointed out here, a condition precedent to engine-life prediction is knowing the statistical distribution of removal for cause of each component, together with that of the entire engine. To a limited extent, these data can be obtained from full-scale component testing, but this method is not economically viable or time efficient. However, these data are available from airline maintenance records together with the engine flight profiles. 
By using the method advocated by Zaretsky (1987) and illustrated by Melis, Zaretsky, and August (1999) for aircraft engine turbine disks, it is possible to extract the necessary engineering and reliability parameters from available airline data bases so as to allow the design engineer to predict the reliability of future products and engines. This method also allows airlines to predict engine life and reliability for their own engines on the basis of their own flight profiles, independent of those of the engine's manufacturer.

\section{SUMMARY OF RESULTS}

The NASA $E^{3}$-Engine was used as the basis for a Weibullbased life and reliability analysis. When limits are placed on stress, temperature, and time for a component's design, the criterion that will define the component's life and thus the engine's life is either high-cycle or low-cycle fatigue. Based on the engine manufacturer's original component-life calculations, the engine's life and reliability were determined on the basis of assumed values of each of the component's cumulative life distributions as represented by a Weibull slope. The lives of the HPT disks and blades were also evaluated as a system and individually. The following results were obtained:

1. Knowing the cumulative statistical distribution (Weibull slope) of each of the engine components is a prerequisite for accurately predicting the life and reliability of an entire engine. As the engine's Weibull slope increases, the predicted life decreases.

2. The predicted engine lives $L_{5}$ of approximately 17,000 and $32,000 \mathrm{hr}$, which depend on the assumed Weibull slope, do correlate with current engine maintenance practices without and with refurbishment, respectively. That is, it can be reasonably anticipated that at one of these time intervals, $5 \%$ of the engines in service will have been removed for repair or refurbishment for cause.

3. The individual HPT blade lives necessary to obtain a bladesystem life $L_{0.1}$ of $9000 \mathrm{hr}$ for Weibull slopes of 3, 6, and 9 were 47,391; 20,652; and 15,658 hr, respectively. Based on these individual blade lives and 1000 engines, or 146,000 blades, in service plus a retirement time for the blades of $18,000 \mathrm{hr}$, constituting the entire blade life with repair, it would be expected that 8,64 , or 512 blades would be removed for cause prior to this time for Weibull slopes of 3, 6, or 9, respectively.

4. For a design life of each of two HPT disks having probable points of failure equal to or greater than $36,000 \mathrm{hr}$ at a probability of survival of $99.9 \%$, the predicted disk system life $L_{0.1}$ can vary from 9408 to $24,911 \mathrm{hr}$, depending on the Weibull slope assumed.

\section{NOMENCLATURE}

$\begin{array}{ll}C & \text { Constant } \\ c & \text { Stress-life exponent }\end{array}$

$e$

$h$

$K_{t}$

$L_{1}, L_{2}$

$\mathbf{L}_{1}, \mathbf{L}_{2}$

$L_{0.1}$

$L_{5}$

$N$

$n$

$p$

$S$

$T$

V

$X$

$X_{\beta}$

$X_{1}, X_{2}$

Z

$\sigma$

$\tau$

\section{Subscripts}

blade

HPT

$n$

O

$\mathrm{RE}$

Reference point, stress, volume, or life

ROT. ST. Rotating structure (disks, drums)

sys $\quad$ System or component probability of survival or life $\beta \quad$ Designates characteristic life or stress

\section{REFERENCES}

August, R., and Zaretsky, E. V. 1993. Incorporating finite-element analysis into component life and reliability. ASME Journal of Mechanical Design 115(4):706-710.

Broman, C. L. 1982. Energy-efficient engine ICLS engine bearings, drives, and configuration: detail design report. National Aeronautics and Space Administration, NASA, CR-167871, Washington, DC.

Davis, D. Y., and Stearns, E. M. 1985. Energy-efficient engine flight propulsion system final design and analysis. National Aeronautics and Space Administration, NASA, CR-168219, Washington, DC.

Halila, E. E., Lenahan, D. T., and Thomas, T. T. 1982. Energyefficient engine high-pressure turbine test hardware: detailed design report. National Aeronautics and Space Administration, NASA, CR-167955, Washington, DC.

Hall, E. J., Lynn, S. R., Heidegger, N. J., and Delaney, R. A. 1998. Energy-efficient engine low-pressure subsystem flow analysis. 
National Aeronautics and Space Administration CR206597. NASA.

Holland Jr., F. A., Zaretsky, E. V., and Melis, M. E. 1998. Probabilistic failure prediction of SCS-6/Ti-15-3 MMC ring. ASME Journal of Mechanical Design 120:714-720.

Ioannides, E., and Harris, T. A. 1985. A new fatigue life model for rolling bearing. ASME Journal of Tribology 107:367-378.

Langer, B. F. 1937. Fatigue failure from stress cycles of varying amplitude. ASME Journal of Applied Mechanics 59:A160 A162.

Lewicki, D. G., Black, J. D., Savage, M., and Coy, J. J. 1986. Fatigue life analysis of a turboprop reduction gearbox. ASME Journal of Mechanisms, Transmissions, Automation, and Design 108:255262.

Lundberg, G., and Palmgren, A. 1947. Dynamic capacity of rolling bearings. Acta Polytechnica, Mechanical engineering series 1, Nr 3, Stockholm, Sweden.

Mahorter, R., London, G., Fowler, S., and Salvino, J. 1985. Life prediction methodology for aircraft gas turbine engine disks. Proceedings of AIAA, SAE, ASME, ASEE 21 st Joint Propulsion Conference, AIAA Paper No. 85-1141. Reston, VA.

Melis, M. E., and Ogonek, J. A. 1995. A life-prediction algorithm implemented in P3 Using PCL. Proceedings of MSC World Users Conference, Paper 19, Session 48. MacNeal-Schwendler, Los Angeles, CA.

Melis, M. E., Zaretsky, E. V., and August, R. 1999. Probabilistic analysis of aircraft gas turbine disk life and reliability. AIAA Journal of Propulsion and Power 15:658-666.

Miner, M. A. 1945. Cumulative damage in fatigue. ASME Journal of Applied Mechanics 12:A159-A164.

Palmgren, A. 1924. The service life of ball bearings. Zectsckrift des Vereines Deutscher Ingenieure 68:339-341.
Poplawski, J. V., Zaretsky, E. V., and Peters, S. M. 2001a. Effect of roller profile on cylindrical roller bearing life prediction. I: Comparison of bearing life theories. STLE Tribology Transactions 44:339-350.

Poplawski, J. V., Zaretsky, E. V., and Peters, S. M. 2001b. Effect of roller profile on cylindrical roller bearing life prediction. II: Comparison of roller profiles. STLE Tribology Transactions 44:471-427.

Weibull, W. 1939a. A statistical theory of the strength of materials. Ingeniors Vetanskaps Akademien-Handlinger, Nr 151. Stockholm, Sweden.

Weibull, W. 1939b. The phenomenon of rupture in solids. Ingeniors Vetanskaps Akademien-Handlinger, Nr 153. Stockholm, Sweden.

Weibull, W. 1951. A statistical distribution function of wide applicability. ASME Journal of Applied Mechanics 18:293-297.

Weibull, W. 1962. Efficient methods for estimating fatigue life distribution of rolling bearings. In J. B. Bidwell, ed. Rolling Contact Phenomena, 252-265. New York: Elsevier.

Zaretsky, E. V. 1987. Fatigue criterion to system design, life and Reliability. AIAA Journal of Propulsion and Power 3:76-83.

Zaretsky, E. V., ed. 1992. STLE life factors for rolling bearings. Society of Tribologists and Lubrication Engineers Publication SP-34. Park Ridge, IL: STLE.

Zaretsky, E. V. 1994. Design for life, plan for death. Machine Design 66:55-59.

Zaretsky, E. V., Poplawski, J. V., and Peters, S. M. 1996. Comparisons of life theories for rolling-element bearings. STLE Tribology Transactions 39:237-248, 501-503.

Zaretsky, E. V. 1998. A. Palmgren revisited: a basis for bearing-life prediction. STLE Lubrication Engineering 54:18-24.

Zaretsky, E. V., Smith, T. E., and August, R. 1989. Effect of design variables, temperature gradients and speed on life and reliability of a rotating disk. ASME Journal of Vibration, Acoustics, Stress and Reliability in Design 111:311-317. 

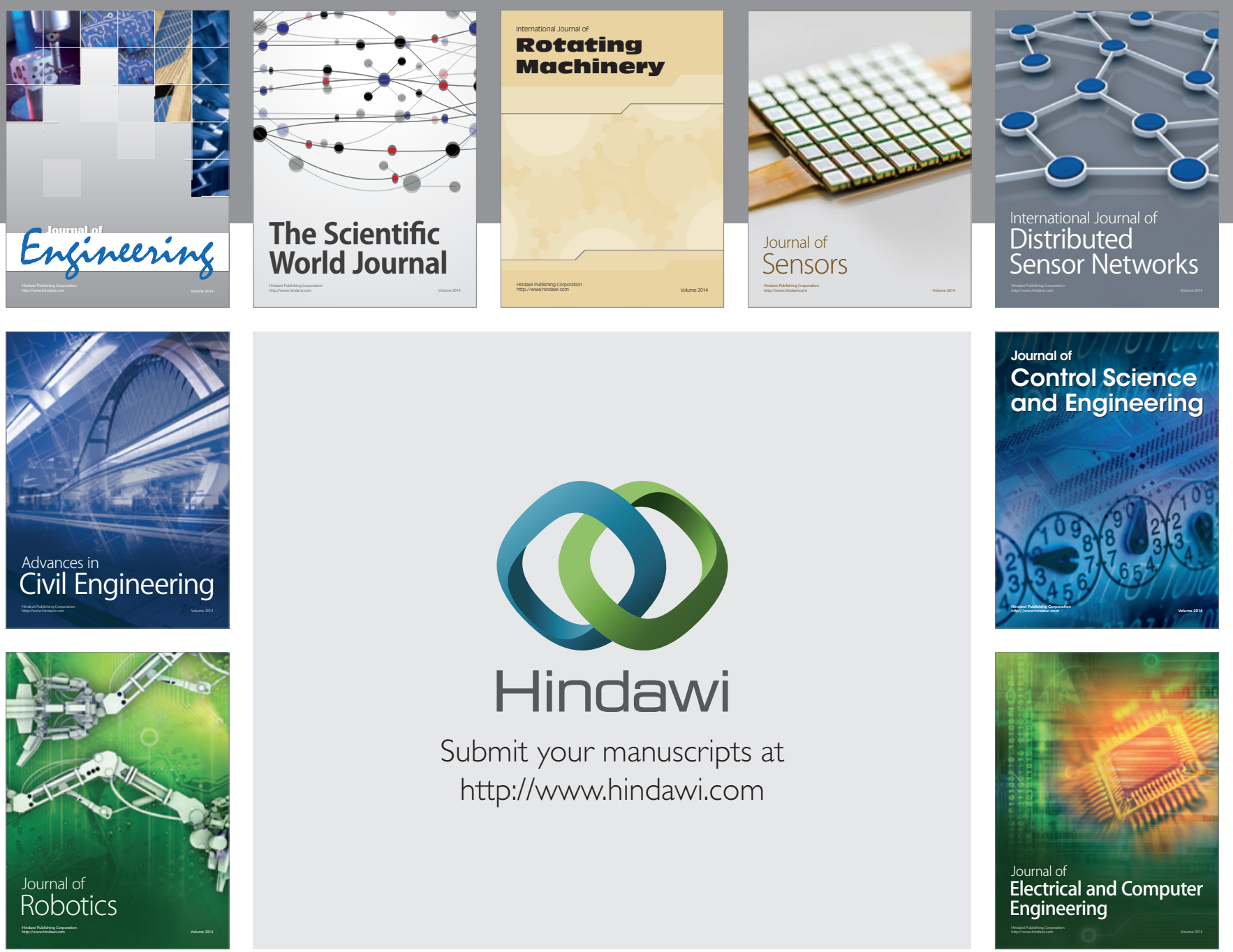

Submit your manuscripts at

http://www.hindawi.com
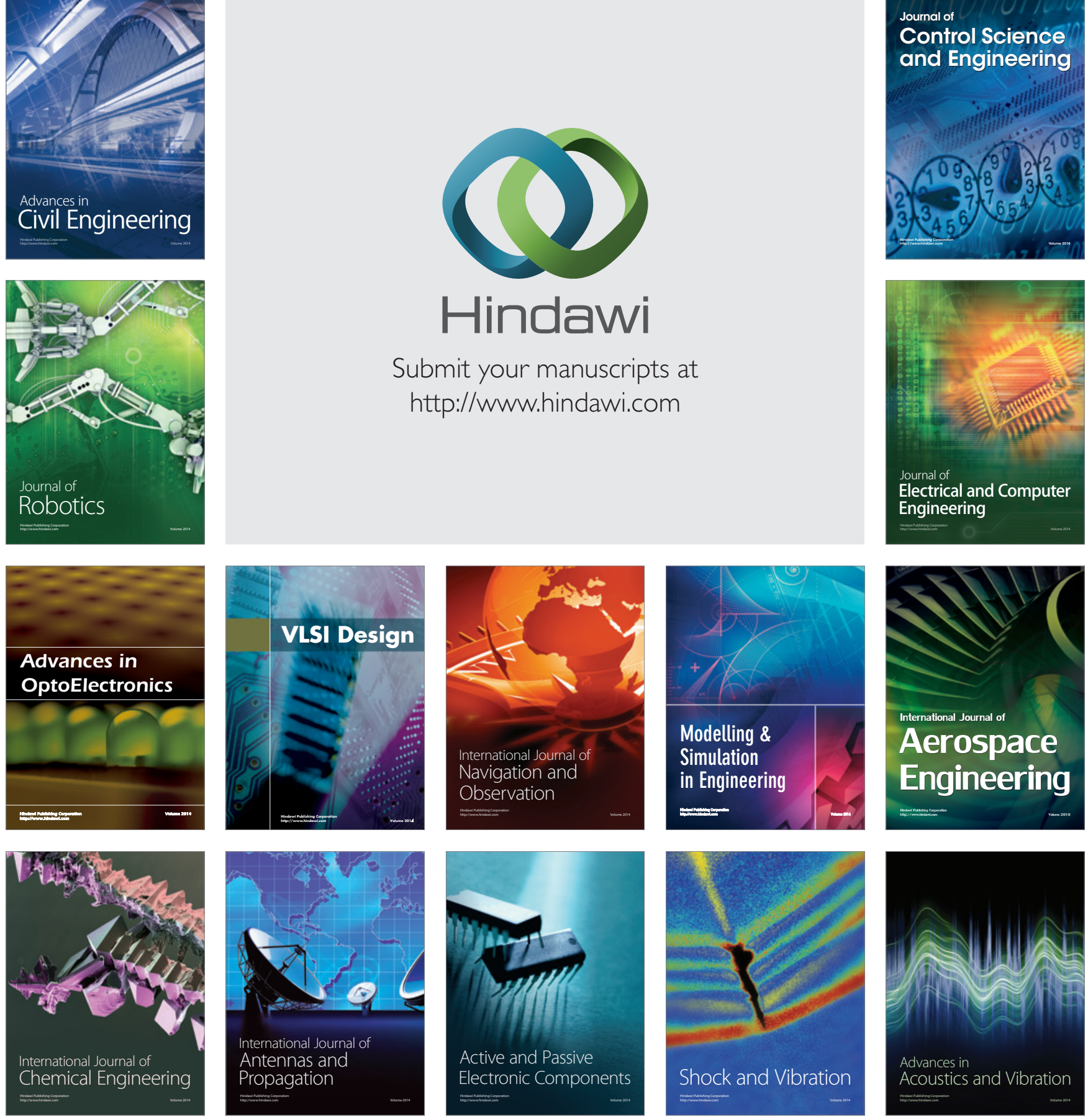